This item was submitted to Loughborough's Research Repository by the author.

Items in Figshare are protected by copyright, with all rights reserved, unless otherwise indicated.

\title{
Effect of anticipation on knee kinematics during a stop-jump task
}

PLEASE CITE THE PUBLISHED VERSION

http://dx.doi.org/10.1016/j.gaitpost.2013.05.027

\section{PUBLISHER}

(c) Elsevier

\section{VERSION}

AM (Accepted Manuscript)

\section{PUBLISHER STATEMENT}

This work is made available according to the conditions of the Creative Commons Attribution-NonCommercialNoDerivatives 4.0 International (CC BY-NC-ND 4.0) licence. Full details of this licence are available at: https://creativecommons.org/licenses/by-nc-nd/4.0/

\section{LICENCE}

CC BY-NC-ND 4.0

\section{REPOSITORY RECORD}

Fong, Daniel Tik-Pui, Mak-Ham Lam, Pik-Kwan Lai, Patrick Shu-Hang Yung, Kwai-Yau Fung, and Kai-Ming Chan. 2019. "Effect of Anticipation on Knee Kinematics During a Stop-jump Task". figshare. https://hdl.handle.net/2134/21244. 


\section{ABSTRACT}

2 Background: The restoration of knee rotational stability after anatomical double

3 bundle anterior cruciate ligament (ACL) reconstruction has been demonstrated in

4 cadaveric model and passive stress test on human, but not yet in dynamic functional

5 biomechanical test performed by human subjects.

6 Purpose: The purpose of the current study was to prospectively investigate the range

7 of tibial rotation of ACL deficient and reconstructed knees during a pivoting task. It was

8 hypothesized that there would be a significant increase in tibial internal rotation of ACL

9 deficient knee compared to the contralateral knee, and the increased rotation would

10 be returned to normal after anatomical double bundle ACL reconstruction.

11 Study design: Cohort study

12 Methods: Ten male subjects with unilateral ACL injury performed a high demanding 13 jump-landing and pivoting task before and after ACL reconstruction with mean follow 14 up of 11 months. The range of tibial rotation of the injured, reconstructed and intact 15 knees during the pivoting movement was measured by an optical motion analysis 16 system. Paired t-tests were performed to investigate any significant difference 17 between the two limbs pre-operatively and post-operatively, and within the injured $18 \operatorname{limb}$ before and after the surgical treatment. Statistical significance was set at $p<0.05$ 19 level.

20 Results: The range of tibial rotation was higher in ACL deficient knee than the intact 21 knee pre-operatively $(p<0.05)$. The increased rotation was reduced in the 22 reconstructed knee after $\mathrm{ACL}$ reconstruction when compared to the deficient knee $23(p<0.05)$. There was no significant difference in the tibial rotation between the intact 24 knee and the reconstructed knee post-operatively $(p>0.05)$.

25 Conclusion: By assessing with a dynamic functional pivoting movement, we 26 demonstrated that the anatomical double bundle ACL reconstruction successfully 
27 restored knee rotational stability from an impaired level.

28 Keywords: Kinematics, rotational instability, rotation, ACL, double bundle 
INTRODUCTION

30 Anterior cruciate ligament (ACL) injury leads to knee instability, mainly in 31 anterior-posterior (AP) translation and axial internal-external rotation. It has been well 32 documented that excessive tibial rotation would follow an ACL excision in cadaveric 33 model ${ }^{1,8,20}$. Clinically, knee instability before and after ACL reconstruction is often 34 examined subjectively by pivot shift test, in which passive valgus and internal rotation 35 stresses are applied to the knee ${ }^{18,22}$. Recently, mechanical devices were developed 36 for objective and biomechanical assessment of knee rotational laxity ${ }^{21,26}$. They 37 provided an easy and non-invasive way by applying a controlled torque to the knee 38 joint, and documenting the knee rotational abnormality. However, these clinical and 39 biomechanical tests were measuring the passive knee joint laxity with relaxed 40 muscles. When a patient performs a dynamic functional movement after returning to 41 sport, it is not only the ligaments but also the muscle contractions that provide the joint 42 stability. There is a need to conduct functional performance test to evaluate the 43 dynamic joint stability during high demanding tasks.

45 The movement of functional test should be specific to the purpose of study. Several 46 kinematics studies, which employed different dynamic movements, investigated patients with unilateral ACL injury. Andriacchi and Dyrby ${ }^{3}$ reported that the external rotation and anterior translation were different between ACL deficient and intact knees in swing phase during walking. On treadmill running, tibial rotation increased with 50 speed in both injured and normal knees ${ }^{5}$. The differences between the knees, 51 however, were not significant. Waite and coworkers ${ }^{33}$ suggested that low demand 52 activity such as walking and running did not produce sufficient stress to initiate knee 53 instability in ACL deficient knee. In a study of assessing functional stability with a high 54 demanding movement, tibial rotation was found not to be restored after single bundle 
55 ACL reconstruction with hamstring or patellar tendon autograft ${ }^{12}$. In the current study,

56 a pivoting task was used to evaluate the effect of anatomical double bundle ACL 57 reconstruction.

In-vitro studies showed that anatomical double bundle ACL reconstruction using hamstring graft restored both AP translation and axial rotation stability ${ }^{23,37}$. With this current technique, clinical studies reported good restoration of joint stability and patient-reported outcomes after a short-term follow-up ${ }^{10,32}$. Moreover, a few studies $^{2,13,16,36}$, which used subjective clinical tests and questionnaires for evaluation, compared between double bundle and single bundle ACL reconstruction. However, among these studies, there is limited knowledge of rotational stability as investigated by objective assessment after anatomical double bundle ACL reconstruction. On the other hand, there were studies ${ }^{29,31}$, using dynamic functional activity, reported that single bundle ACL reconstruction could not restore rotational stability. Therefore, the purpose of the current study was to prospectively investigate the range of tibial rotation of $A C L$ deficient and reconstructed knees during a high demanding task. The

71 contralateral intact knee was used as a control. It was hypothesized that there would 72 be a significant increased tibial rotation in ACL deficient knee and it would be returned to normal after anatomical double bundle ACL reconstruction.

METHOD

Subject: Ten male subjects (age $=27.2 \pm 4.7 \mathrm{yr}$, height $=1.76 \pm 0.1 \mathrm{~m}$, body mass $=$ $69.1 \pm 9.2 \mathrm{~kg}$ ) with unilateral ACL injury (six right knees and four left knees) were recruited in the study. All the subjects were recruited in our sports clinic. When patients were confirmed with unilateral $A C L$ rupture, they were scanned with exclusion criteria. ACL rupture was confirmed either by arthroscopy, magnetic resonance 
81 imaging or clinical examination. Exclusion criteria included the presence of bone

82 fractures, complex meniscal injury, ligamentous injuries of the involved knee and previous surgery on either knee. All subjects reported knee joint instability during sports and were suggested to receive surgical treatment. All injuries were sport-related and all subjects participated at least one time per week in their sports before the injury. The preoperative and postoperative clinical data was shown in Table 1. The university ethics committee approved the study. Informed consents were obtained from each subject before the study.

Surgical technique: In all subjects, anatomical double bundle ACL reconstructions were performed by two authors who have more than 10 years experiences in performing $\mathrm{ACL}$ reconstruction. The operating knee was put on the operating table with a foot rest and lateral thigh support at 90 degrees of flexion. The operation was performed after inflating the tourniquet. The hamstring grafts (gracilis and semi-tendinosus) were harvested through an incision over the ipsilateral tibia and braided with ultrabraid 2 (Smith and Nephew Endoscopy, Massachusetts, USA) to each tendon grafts. A diagnostic arthroscopy was performed by using the anterolateral and anteromedial portals. After confirming the rupture of anteromedial (AM) and posterolateral $(P L)$ bundles, the ACL stump was debrided and the foot prints of $A M$ and PL bundles were identified and marked by radiofrequency probe. The footprint of the ACL was identified by locating the lateral intercondylar ridge and the lateral

102 bifurcate ridge as suggested by previous studies ${ }^{17,24}$. The AM femoral tunnel was 103 prepared through the anteromedial portal with the aid of a $6 \mathrm{~mm}$ offset guide, the 104 guide pin was placed at the footprint of AM bundle and reamed to $4.5 \mathrm{~mm}$ diameter for 105 the passage of the endobutton (Smith and Nephew Endoscopy, Massachusetts, USA). 106 It was further reamed to $6 \mathrm{~mm}$ or $7 \mathrm{~mm}$ diameter and the integrity of the outer cortex 
107 was preserved. The diameter and length of the tunnel depended on the graft size and

108 the patient anatomy. After creating the tunnel for AM bundle, the knee was then flexed

109 to 110 degrees. An accessory anteromedial portal was created according to the 110 guidance of a spinal needle which was used to aim the footprint of the PL bundle. A $1112.4 \mathrm{~mm}$ guide pin was inserted according to the footprint of the PL bundle. The PL 112 femoral tunnel, which varied from $5 \mathrm{~mm}$ to $6 \mathrm{~mm}$ in diameter, was then created through 113 the accessory anteromedial portal by the endobutton reamer and the $5 \mathrm{~mm}$ or $6 \mathrm{~mm}$ 114 reamer. The bone bridge between the two tunnels was at least $2 \mathrm{~mm}$. For the tibial 115 tunnels of $\mathrm{AM}$ and PL bundles, $45^{\circ}$ and $55^{\circ}$ tibial jig (Smith and Nephew Endoscopy, 116 Massachusetts, USA) was used respectively. The ACL remnant was used as a guide 117 to identify the footprint of ACL. The tibial tunnel of PL bundle was created by inserting 118 a $2.4 \mathrm{~mm}$ guide pin through a 55 degrees tibial jig. The guide pin was aimed to the 119 footprint of $\mathrm{ACL}$ and around $6 \mathrm{~mm}$ to $7 \mathrm{~mm}$ anterior to the PCL. Another $2.4 \mathrm{~mm}$ guide 120 pin was inserted through 45 degrees tibial jig, aimed around $9 \mathrm{~mm}$ away (anterior and 121 medial) from the guide pin for PL tunnel. According to the size of the graft, it was then 122 further reamed to 5 or $6 \mathrm{~mm}$ and 6 or $7 \mathrm{~mm}$ in diameter for the PL and AM tibial 123 tunnels respectively. The bone bridge between the two tibial tunnels was aimed for 124 around $2 \mathrm{~mm}$. A double throws Gracilis and semitendinosis tendons were used for PL 125 and AM bundle reconstructions respectively. Graft passage was completed for the PL 126 bundle followed by the AM bundle. On the femoral side, PL bundle was fixed by $15 \mathrm{~mm}$

127 Endobutton loop (Smith and Nephew Endoscopy, Massachusetts, USA), while AM 128 bundle was fixed by $15 \mathrm{~mm}$ or $20 \mathrm{~mm}$ Endobutton loop. The PL bundle was tensioned 129 at $15^{\circ}$ of flexion and the AM bundle at $60^{\circ}$ of flexion. On the tibial side, bioabsorbable 130 interference screws were used to fix each bundle individually and staples were used 131 to fix both grafts over the medial surface of tibia. The arthroscopic image and 
132 postoperative x-ray picture was shown in Figure 1. After ACL reconstruction, all

133 patients completed a standard rehabilitation program $^{30}$.

134

135 Experimental procedure: All subjects were assessed before and after ACL

136 reconstruction with a follow-up of $10.3 \pm 3.9$ months. An optical motion analysis

137 system with eight cameras (VICON 624, UK) was used to record the three

138 dimensional rotation movements of lower extremities at $120 \mathrm{~Hz}$ capturing frequency.

139 The system was calibrated on the same day of testing and the mean residual was less

140 than $1 \mathrm{~mm}$. If not, the system was recalibrated. Synchronized force-plate (AMTI OR6-7,

141 Massachusetts, USA) data was collected at the centre of the capture volume at

$1421080 \mathrm{~Hz}$. A fifteen-marker model ${ }^{6}$ was adopted to collect lower limb kinematics during

143 movements. Skin reflective markers with $9 \mathrm{~mm}$ diameter were placed at anatomical

144 landmarks including anterior superior iliac spines (ASIS), sacrum, greater trochanter,

145 femoral epicondyle, tibial tubercle, lateral malleolus, heel and fifth metatarsal head on

146 both limbs. Anthropometric data including body mass, ASIS breadth, thigh and calf

147 length, midthigh and calf circumference, knee diameter, foot breadth and length,

148 malleolus height and diameter were measured for kinematics calculation. The

149 reliability of the overall procedure was reported to be less than 2.4 degrees for within

150 day measures ${ }^{34}$.

151

152 Experimental task: Before performing the movement, a trial of standing anatomical

153 position was recorded. Every subject was instructed by the same tester to stand with

154 both feet in shoulder width and align the shank and foot segment to a neutral position.

155 This calibration file provided a definition of zero degree for all segmental movements.

156 Both limbs were tested individually. The subjects were asked to leave off a platform,

157 which was $40 \mathrm{~cm}$ height and placed $10 \mathrm{~cm}$ behind the force plate, and land with both 
158 feet on the ground, with only the testing foot on the force-plate. After the foot contact,

159 the subjects pivoted 90 degrees to the lateral side of testing leg, which also acted as

160 the core leg during pivoting. The subjects were instructed to run away with their

161 maximum effort for three steps after completing the pivoting movement (Figure 2).

162

163 Data collection and reduction: The evaluation period was defined from the first foot

164 contact to the take-off of the testing leg on the ground. A foot contact was determined

165 by the force plate when the vertical ground reaction force exceeded $5 \%$ of the 166 subject's body weight. Three dimensional coordinates of every marker were exported

167 from the VICON software. Together with the anthropometric measurements, the knee

168 joint kinematics was then calculated ${ }^{6}$. All calculations were conducted using self

169 compiled program (Mathworks, Massachusetts, USA). The main dependent variable

170 in the current study was range of tibial rotation during pivoting movement, which was

171 defined as the difference between the lowest tibial internal rotation after landing and

172 the highest tibial internal rotation within the foot contact period ${ }^{29}$.

173

174 Data analysis: Paired t-tests were performed to investigate any significant difference

175 between the two limbs pre-operatively and post-operatively, and within the injured

176 limb before and after the anatomical double bundle ACL reconstruction. Power

177 analysis was conducted if there was no significant difference between the

178 reconstructed knee and the intact knee after reconstruction. The level of significance

179 and study power were set at 0.05 and 0.8 respectively.

180

\section{RESULTS}

182 During the pivoting phase, the tibia internally rotated to a maximum degree (Figure 3).

183 For the range of tibial rotation, there was a significant $(P=0.005)$ increase in the 
184 deficient knee $(12.6 \pm 4.5$ degrees $)$ when compared to the intact knee $(7.9 \pm 3.1$

185 degrees) pre-operatively. This increased tibial rotation significantly $(p=0.035)$

186 decreased to $8.9 \pm 3.0$ degrees in the reconstructed knee and did not differ to that of

187 intact knee (8.2 \pm 2.6 degrees) after $A C L$ reconstruction (Figure 4). Since there was

188 no significant difference between the reconstructed knee and the intact knee after

189 reconstruction, power analysis was conducted (true difference: 2 degrees; correlation:

$190 \quad 0.27$ ) and the statistical power was reported to be 0.81 between the two groups.

\section{DISCUSSION}

193 In this study, the increased tibial rotational movement in ACL deficient knee and the

194 restoration of this movement after ACL reconstruction were demonstrated. The

195 different between intact and deficient knees of the current study supported the first

196 hypothesis while the decreased tibial rotation and the adequate statistical power also

197 support the second hypothesis of this study.

198

199 Our findings supported previous studies ${ }^{7,12,29,31}$ that showed knee rotational instability 200 of ACL deficient knee and reconstructed knee with single bundle technique. In two 201 studies ${ }^{12,29}$ with similar protocol to the present study, the tibial rotation of deficient 202 knee was significantly higher than that of intact knee. While those subjects were 203 instructed to walk followed by the pivoting movement, our subjects were instructed to 204 run instead. We believed that the task in our study provided a higher rotational stress 205 to the knee. However, the increased tibial rotation found in the current study was not 206 as high as that in these two previous studies. It might be due to the difference in the 207 time from injury to assessment. The subjects recruited in this study were acute injury 208 cases and those in the two studies were chronic injury cases. The subjects in this 209 study might perform cautiously in the preoperative assessment. Another studies 
210 employing different functional activities such as downhill running ${ }^{31}$ and single leg

211 hopping $^{7}$ also showed abnormal rotational motion after ACL reconstruction. When

212 comparing the study design, all the subjects in our study were assessed prospectively

213 before and after ACL reconstruction. The variations between study group and control

214 group were minimized to affect the result as contralateral intact knee was used as a 215 control.

216

217 Anatomic ACL reconstruction ${ }^{15}$ aims to reconstruct the original $A C L$ with normal 218 kinematics in all six degree of freedom, including mediolateral and anteroposterior 219 translation, and axial rotation. However, in vitro ${ }^{4,19,35}$ and in vivo ${ }^{7,12,29,31}$ studies showed 220 that tibial rotation was not restored by single bundle ACL reconstruction. One of the 221 reasons suggested that only AM bundle was replicated, resulting in insufficient 222 rotational control to the knee. In the current study, all subjects were treated with 223 anatomical double bundle ACL reconstruction, in which both AM and PL bundles were 224 reconstructed to mimic the original ACL anatomy. In addition to the AM bundle, PL 225 bundle might provide a role in the stabilization of the knee against a combined rotatory 226 load $^{11}$. When evaluating double bundle ACL reconstruction with a high demanding 227 movement in this study, the significant decrease in range of tibial rotation of the 228 reconstructed knee suggested the effectiveness of rotational control of such 229 anatomical reconstruction. To better demonstrate the superiority of double bundle 230 technique as well as the effect of PL bundle, future study with large scale randomized 231 controlled trial comparing the effect of single bundle and double bundle ACL 232 reconstruction on functional stability was suggested.

234 Functional test should be the ultimate step for evaluating ACL reconstruction since it 235 involves real-life loading that human joints are exposed to in daily activity or even 
236 sport motion. Although dynamic functional test was commonly employed ${ }^{9}$, previous

237 studies, however, mainly focused on functional performance. Muscle strength was

238 one of the performance indexes during rehabilitation, in which there were positive 239 association between thigh muscles and functional outcome of the knee ${ }^{25}$. Other

240 functional tests such as vertical jump, figure of eight and stairs running were used as 241 assessment after $A C L$ reconstruction ${ }^{28}$. All these functional outcomes were expressed

242 as strength and ability that a patient would achieve. Instead, joint functional stability 243 should be investigated through function test such as running ${ }^{31}$ and jumping ${ }^{7}$. In the 244 present study, a high demanding sport movement was used to investigate the effect of 245 anatomical double bundle ACL reconstruction on knee rotational stability. The stability 246 was expressed as tibial rotation during a pivoting movement and the result of 247 excessive rotation before ACL reconstruction was in line with previous study ${ }^{28}$. 248 Functional test with motion analysis would be a good tool to evaluate patients with 249 knee instability, such as after knee ligamentous injury.

251 The limitation in the present study involved known drawbacks of motion analysis, 252 including the movement of skin markers ${ }^{27}$. During the procedure, the inter-tester error 253 was minimized by having the same technician placing the skin markers and 254 measuring all anthropometric data. A standing offset trial to define zero degree for all 255 segmental movements was collected to avoid subtle misalignment of the knee joint. 256 Moreover, it was reported that tibial rotation was reliably measured in a similar 257 previous study ${ }^{34}$. Typical error values $\left(<2.9^{\circ}\right)$ were less than the usual group 258 differences in rotational excursion reported in the literature. Furthermore, to avoid 259 variation in the complicated surgical technique ${ }^{14}$ between different surgeons, two 260 experienced orthopaedic surgeons preformed all reconstructions in this study. Lastly, 
261 to avoid unnecessarily subject variations the current study employed a prospective

262 cohort design, in which the same injury knee was compared before and after the 263 reconstruction. The intact knee of the same individual was used as a control.

264

\section{CONCLUSION}

266 It was concluded that there was an increased tibial rotation in ACL deficient knee. By 267 using a dynamic functional biomechanical assessment in this study, we demonstrated 268 that the reconstructed knee by anatomical double bundle ACL reconstruction 269 successfully restored functional knee rotational stability during a pivoting movement. 


\section{FIGURE CAPTIONS}

271 Figure 1: The arthroscopic images (1, ACL footprint of femoral side at 90 degrees of

272 knee flexion; 2, femoral tunnels at 110 degrees of knee flexion, viewed from

273 anteromedial portal; 3, tibial tunnels created by insertion 2 guide pins by tibial jig at 55

274 and 45 degrees for PL and AM bundles respectively; 4, graft passage viewed from

275 anterolateral portal) and postoperative x-ray picture of the anatomical double bundle

276 ACL reconstruction.

277 Figure 2: The video sequence (1, initial position; 2, jumping; 3, landing; 4, pivoting; 5,

278 push-off; 6, running) of the jump-landing and pivoting task, assessing the right knee of

279 the patient.

280 Figure 3: Vertical ground reaction force (top), knee flexion (middle) and tibial rotation

281 (bottom) during the entire stance phase of the high demanding jump-landing and

282 pivoting task from one typical ACL deficient knee.

283 Figure 4: Range of tibial rotation during pivoting movement before and after ACL

284 reconstruction. Asterisks $\left(^{*}\right)$ indicate a significant difference suggested by paired t-test

285 ( $p=0.005$ for pre-op intact and pre-op deficient; $p=0.035$ for pre-op deficient and 286 post-op reconstructed).

\section{TABLE CAPTIONS}

288 Table 1: Preoperative and postoperative clinical data of all subjects. 
1. Amis AA, Scammell BE. Biomechanics of intra-articular and extra-articular reconstruction of the anterior cruciate ligament. Journal of Bone and Joint Surgery - British Volume. 1993;75:812-817.

2. Aglietti P, Giron F, Losco M, Cuomo P, Ciardullo A, Mondanelli N. Comparison between single- and double-bundle anterior cruciate ligament reconstruction: a prospective, randomized, single-binded clinical trial. American Journal of Sports Medicine. 2010;38:25-34.

3. Andriacchi TP, Dyrby CO. Interactions between kinematics and loading during walking for the normal and ACL deficient knee. Journal of Biomechanics. 2005;38:293-8.

4. Colombet P, Robinson J, Christel P, Franceschi JP, Djian P. Using navigation to measure rotation kinematics during ACL reconstruction. Clinical Orthopaedics and Related Research. 2007;454:59-65.

5. Czerniecki JM, Lippert F,Olerud JE. A biomechanical evaluation of tibiofemoral rotation in anterior cruciate deficient knees during walking and running. Am J Sports Med. 1988;16:327-31.

6. Davis RB, Ounpuu S, Tyburski D,Gage JR. A gait analysis data collection and reduction technique. Human Movement Science. 1991;10:575-587.

7. Deneweth JM, Bey MJ, McLean SG, Lock TR, Kolowich PA, Tashman S. Tibiofemoral joint kinematics of the anterior cruciate ligament-reconstructed knee during a single-legged hop landing. American Journal of Sports Medicine. 2010;38:1820-1828.

8. Duthon VB, Barea C, Abrassart S, Fasel JH, Fritschy D,Menetrey J. Anatomy of the anterior cruciate ligament. Knee Surgery Sports Traumatology Arthroscopy. 2006;14:204-213.

9. Fitzgerald GK, Lephart SM, Hwang JH,Wainner RS. Hop tests as predictors of dynamic knee stability. Journal of Orthopaedic and Sports Physical Therapy. 2001;31:588-97.

10. Fu FH, Shen W, Starman JS, Okeke N,Irrgang JJ. Primary anatomic double-bundle anterior cruciate ligament reconstruction: a preliminary 2-year prospective study. Am J Sports Med. 2008;36:1263-74.

11. Gabriel MT, Wong EK, Woo SL, Yagi M,Debski RE. Distribution of in situ forces in the anterior cruciate ligament in response to rotatory loads. J Orthop Res. 2004;22:85-9.

12. Georgoulis AD, Ristanis S, Chouliaras V, Moraiti C,Stergiou N. Tibial rotation is not restored after ACL reconstruction with a hamstring graft. Clinical Orthopaedics and Related Research. 2007;454:89-94. 
13. Jarvela T. Double-bundle versus single-bundle anterior cruciate ligament reconstruction: a prospective, randomize clinical study. Knee Surg Sports Traumatol Arthrosc. 2007;15:500-507

14. Karlsson J. ACL injuries: unanswered questions--are there any solutions? Knee Surg Sports Traumatol Arthrosc. 2010;18:275-6.

15. Karlsson J. Anatomy is the key. Knee Surg Sports Traumatol Arthrosc. 2010;18:1.

16. Kondo E, Yasuda K, Azuma H, Tanabe Y, Yagi T. Prospective clinical comparisons of anatomic double-bundle versus singe-bundle anterior cruciate ligament reconstruction procedures in 328 consecutive patients. American Journal of Sports Medicine. 2008;36:1675-1687.

17. Kopf S, Musahl V, Tashman S, Szczodry M, Shen W, Fu, FH. A systematic review of the femoral origin and tibial insertion morphology of the ACL. Knee Surg Sports Traumatol Arthrosc. 2009;17:213-219.

18. Lam MH, Fong DT, Yung P, Ho EP, Chan WY,Chan KM. Knee stability assessment on anterior cruciate ligament injury: Clinical and biomechanical approaches. Sports Med Arthrosc Rehabil Ther Technol. 2009;1:20.

19. Li G, Papannagari R, DeFrate LE, Yoo JD, Park SE, Gill TJ. Comparison of the ACL and ACL graft forces before and after ACL reconstruction: an in-vitro robotic investigation. Acta orthopaedica. 2006;77:267-274.

20. Lipke JM, Janecki CJ, Nelson CL, McLeod P, Thompson C, Thompson J, Haynes DW. The role of incompetence of the anterior cruciate and lateral ligaments in anterolateral and anteromedial instability. A biomechanical study of cadaver knees. Journal of Bone and Joint Surgery - American Volume. 1981;63:954-960.

21. Lorbach O, Wilmes P, Maas S, Zerbe T, Busch L, Kohn D,Seil R. A non-invasive device to objectively measure tibial rotation: verification of the device. Knee Surg Sports Traumatol Arthrosc. 2009;17:756-62.

22. Lubowitz JH, Bernardini BJ,Reid JB, 3rd. Current concepts review: comprehensive physical examination for instability of the knee. American Journal of Sports Medicine. 2008;36:577-94.

23. Mae T, Shino K, Miyama T, Shinjo H, Ochi T, Yoshikawa H, Fujie H. Singleversus two-femoral socket anterior cruciate ligament reconstruction technique: Biomechanical analysis using a robotic simulator. Arthroscopy. 2001;17:708-716.

24. Martins CAQ, Kropf EJ, Shen W, van Eck CF, Fu FH. The concept of anatomic anterior cruciate ligament reconstruction. Operative Technique in Sports Medicine. 2009;16:104-115 
25. Moisala AS, Jarvela T, Kannus P,Jarvinen M. Muscle strength evaluations after ACL reconstruction. International Journal of Sports Medicine. 2007;28:868-72.

26. Musahl V, Bell KM, Tsai AG, Costic RS, Allaire R, Zantop T, Irrgang JJ,Fu FH. Development of a simple device for measurement of rotational knee laxity. Knee Surgery Sports Traumatology Arthroscopy. 2007;15:1009-12.

27. Reinschmidt C, van den Bogert AJ, Nigg BM, Lundberg A,Murphy N. Effect of skin movement on the analysis of skeletal knee joint motion during running. Journal of Biomechanics. 1997;30:729-32.

28. Risberg MA,Ekeland A. Assessment of functional tests after anterior cruciate ligament surgery. Journal of Orthopaedic and Sports Physical Therapy. 1994;19:212-7.

29. Ristanis S, Stergiou N, Patras K, Vasiliadis HS, Giakas G,Georgoulis AD. Excessive tibial rotation during high-demand activities is not restored by anterior cruciate ligament reconstruction. Arthroscopy. 2005;21:1323-9.

30. Shelbourne KD, Nitz P. Accelerated rehabilitation after anterior cruciate ligament reconstruction. American Journal of Sports Medicine. 1990;18:292-299.

31. Tashman S, Collon D, Anderson K, Kolowich P, Anderst W. Abnormal rotational knee motion during running after anterior cruciate ligament reconstruction. American Journal of Sports Medicine. 2004;32:975-983.

32. Toritsuka Y, Amano H, Kuwano M, Iwai T, Mae T, Ohzono K,Shino K. Outcome of double-bundle ACL reconstruction using hamstring tendons. Knee Surg Sports Traumatol Arthrosc. 2009;17:456-63.

33. Waite JC, Beard DJ, Dodd CA, Murray DW,Gill HS. In vivo kinematics of the ACL-deficient limb during running and cutting. Knee Surgery Sports Traumatology Arthroscopy. 2005;13:377-84.

34. Webster KE, McClelland JA, Wittwer JE, Tecklenburg K,Feller JA. Three dimensional motion analysis of within and between day repeatability of tibial rotation during pivoting. Knee. In-press;

35. Woo SL, Kanamori A, Zeminski J, Yagi M, Papageorgiou C,Fu FH. The effectiveness of reconstruction of the anterior cruciate ligament with hamstrings and patellar tendon. A cadaveric study comparing anterior tibial and rotational loads. Journal of Bone and Joint Surgery - American Volume. 2002;84-A:907-14.

36. Yagi M, Kuroda R, Magamune K, Yoshiya S, Kurosaka M. Double-bundle ACL reconstruction can improve rotational stability. Clinical orthopaedics and related research. 2007;454:100-107.

37. Yagi M, Wong EK, Kanamori A, Debski RE, Fu FH,Woo SL. Biomechanical analysis of an anatomic anterior cruciate ligament reconstruction. American Journal of Sports Medicine. 2002;30:660-6. 


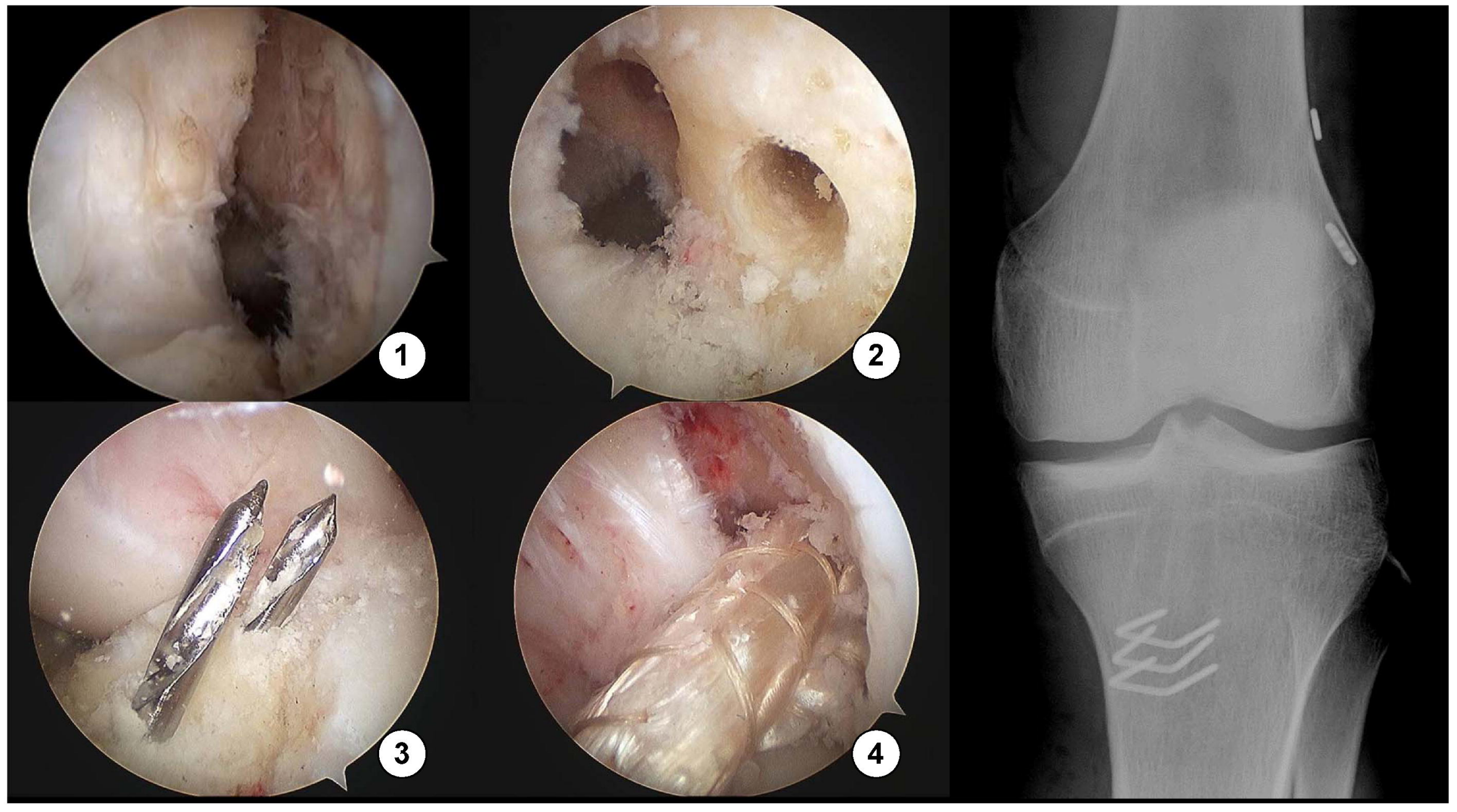




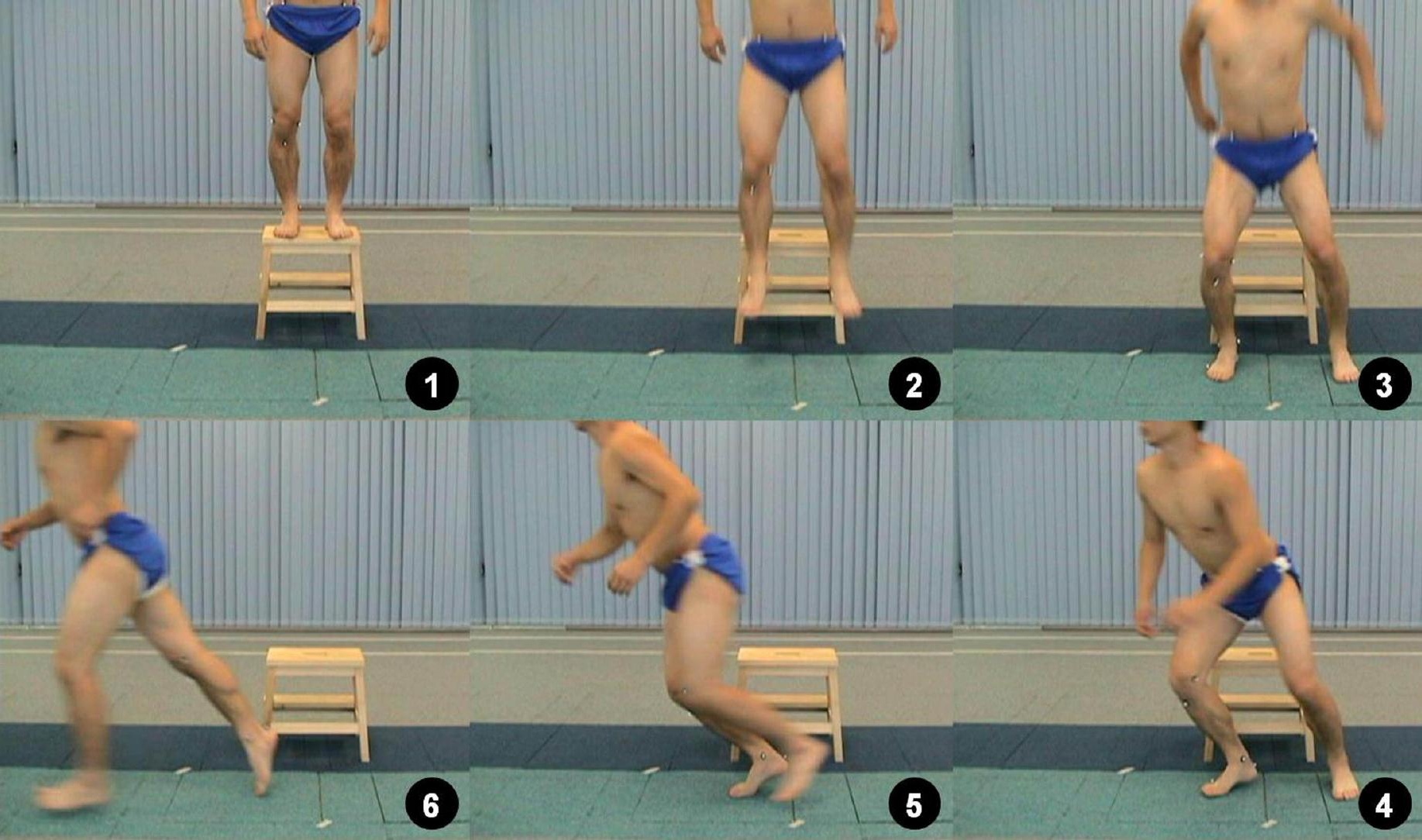




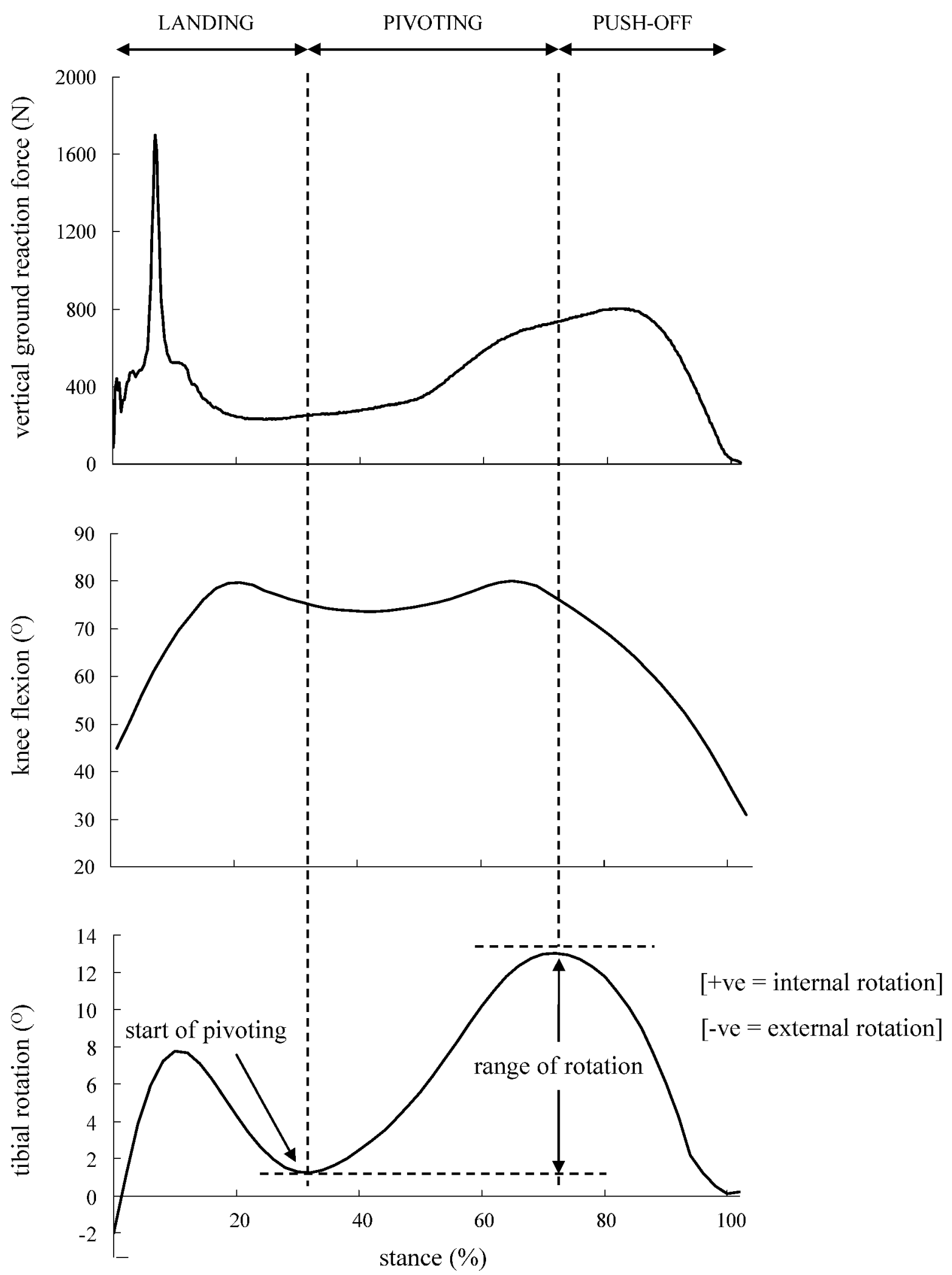




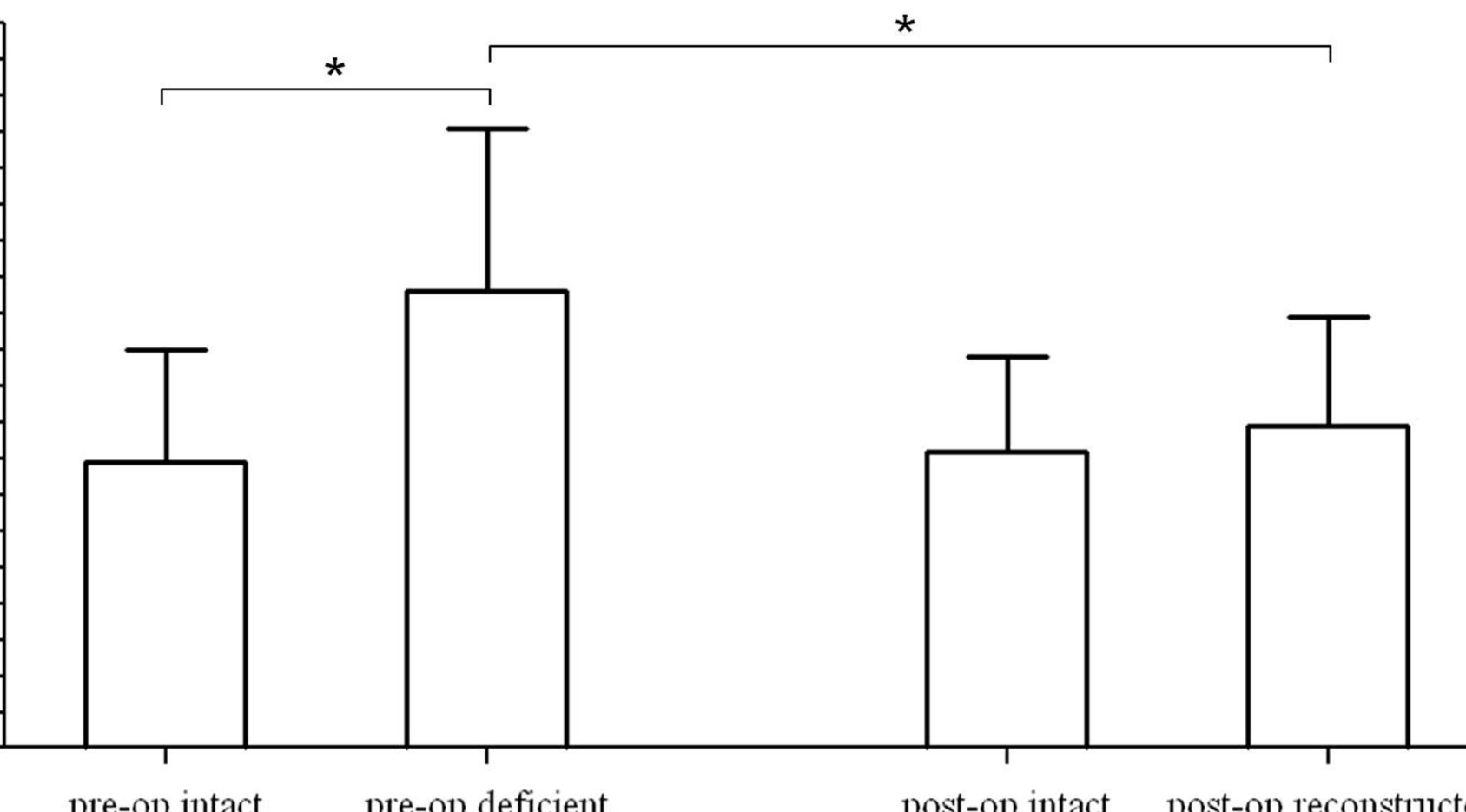




\begin{tabular}{|c|c|c|c|c|c|c|c|c|c|c|c|c|c|c|c|}
\hline \multirow[t]{2}{*}{ Subject } & \multirow{2}{*}{$\begin{array}{l}\text { Injured } \\
\text { knee }\end{array}$} & \multirow{2}{*}{$\begin{array}{l}\text { Time from } \\
\text { injury to } \\
\text { pre-op } \\
\text { assessment } \\
\text { (month) }\end{array}$} & \multirow{2}{*}{$\begin{array}{l}\text { Time from } \\
\text { surgery to } \\
\text { post-op } \\
\text { assessment } \\
\text { (month) }\end{array}$} & \multicolumn{6}{|c|}{ Preoperative assessment } & \multicolumn{6}{|c|}{ Postoperative assessment } \\
\hline & & & & IKDC & Lysholm & $\begin{array}{l}\text { KT1000 } \\
(\mathrm{mm})^{*}\end{array}$ & $\begin{array}{l}\text { Lachman } \\
\text { test }\end{array}$ & $\begin{array}{l}\text { Anterior } \\
\text { drawer } \\
\text { test }\end{array}$ & $\begin{array}{l}\text { Pivot } \\
\text { shift } \\
\text { test }\end{array}$ & IKDC & Lysholm & $\begin{array}{l}\text { KT1000 } \\
(\mathrm{mm})^{*}\end{array}$ & $\begin{array}{l}\text { Lachman } \\
\text { test }\end{array}$ & $\begin{array}{l}\text { Anterior } \\
\text { drawer } \\
\text { test }\end{array}$ & $\begin{array}{l}\text { Pivot } \\
\text { shift } \\
\text { test }\end{array}$ \\
\hline Lui MW & $\mathrm{L}$ & 11 & 7 & 47.1 & 90 & 8.5 & 3 & 2 & 2 & 100 & 99 & 1.5 & 0 & 0 & 0 \\
\hline Lam SP & $\mathrm{R}$ & 3 & 18 & 74.7 & 85 & 4.5 & 3 & 3 & 2 & 100 & 100 & 0 & 0 & 0 & 0 \\
\hline Lam WK & $\mathrm{L}$ & 5 & 10 & 74.7 & 85 & 5.5 & 3 & 2 & 2 & 79.3 & 99 & 1.5 & 0 & 0 & 0 \\
\hline Chan SY & $\mathrm{L}$ & 4 & 12 & 74.7 & 80 & 2.5 & 3 & 3 & 2 & 80.5 & 100 & 2.5 & 0 & 0 & 0 \\
\hline Mak KL & $\mathrm{R}$ & 9 & 7 & 74.7 & 85 & 8.5 & 3 & 2 & 3 & 74.8 & 90 & 3 & 1 & 1 & 0 \\
\hline Lam CK & $\mathrm{R}$ & 5 & 15 & 79.3 & 84 & 0 & 3 & 2 & 2 & 100 & 98 & 1 & 0 & 0 & 0 \\
\hline Lam C & $\mathrm{L}$ & 5 & 7 & 69 & 80 & 3.5 & 2 & 2 & 1 & 100 & 100 & 1.5 & 0 & 1 & 1 \\
\hline Fung SW & $\mathrm{R}$ & 4 & 12 & 73.6 & 80 & 4.5 & 3 & 3 & 2 & 93.3 & 98 & 1.5 & 0 & 0 & 0 \\
\hline Chan CK & $\mathrm{R}$ & 2 & 7 & 73.6 & 75 & 5.5 & 3 & 3 & 3 & 100 & 100 & 1 & 0 & 0 & 0 \\
\hline Yu CY & $\mathrm{R}$ & 3 & 8 & 66.7 & 85 & 7 & 3 & 3 & 2 & 93.3 & 90 & 6 & 1 & 1 & 1 \\
\hline Mean(SD) & - & $5.1(2.8)$ & $10.3(3.9)$ & $70.8(9.0)$ & $82.9(4.2)$ & $5.0(2.6)$ & - & - & - & $92.1(10.1)$ & $97.4(4.0)$ & $2.0(1.6)$ & - & - & - \\
\hline
\end{tabular}

* Difference between both knees at $30 \mathrm{lb}$ anterior force. 